\title{
IX.
}

\section{Ein Fall von multilokulärer Zyste des Netzes.}

(Aus dem Pathologischen Institut der Universität Krakan.)

Von

Henrietta Karaś aus Warschau.

(Mit 3 Textfiguren.)

Die Zystenbildungen des Bauchfells gehören zu relativ seltenen Vorkommnissen, und aus diesem Grunde finden wir in den älteren Lehr- und Handbüchern der pathologischen Anatomie über dieselbe nur kurz gehaltene Anmerkungen. Immer zahlreichere Beschreibungen solcher Fälle in neuerer Zeit führten zu einer in den neueren Werken angeführten Klassifizierung der Zystenbildungen des Bauchfells auf Grund des verschiedenen Ursprunges derselben. So unterscheidet Ziegler $^{1}$ (Lehrb. d. path. An. 1902) Zysten mit epithelialer und solche mit endothelialer Auskleidung. $\mathrm{Zu}$ den ersteren gehören solche, die am Peritonaeum in der Gegend der inneren weiblichen Genitalorgane vorgefunden werden, sowie anch die sog. Enterokystome. Was die letzteren anbetrifft, so unterscheidet Ziegler ihrer mehrere Arten. So werden vor allem in der Bauchhöhle mitunter dünnwandige, traubenförmig angeordnete, gestielte Bläschen vorgefunden. Es sind dies die durch Ausdehnung der Lymphgefäße entstandenen Lymph- oder Chyluszysten oder neoplastische zystische Lymphangiome. Sodann findet man in manchem sonst normalen Peritonaeum mit Endothel anisgekleidete Zysten verschiedener Größe. Endljch führt Ziegler auch zystische Räume mit Endothelauskleidung an, welche sich zwischen Verwachsungen des Peritonaeums bilden.

Von den Bindegewebskapseln des Echinokokkus abgesehen, finden wir in der Literatur Beschreibungen folgender Arten von Peritonäalzysten:

1. Enterokystome und ähnliche Bildungen entodermalen Ursprunges, entstanden durch Entwicklungsabnormitäten.

2. Retentionslymphzysten.

3. Neoplastische zystische Lymphangiome. 
4. Zystische Lymphangioendotheliome - welche Bezeichnung, nebenbei bemerkt, bis jetzt nur in einem Falle angewendet wurde (Nager) ${ }^{25}$.

5. Zystchen, ausgekleidet mit zylindrischem Flimmerepithel, welche bis jetzt nur am Peritonaeum des kleinen Beckens and der inneren weiblichen Genitalorgane vorgefunden wurden.

Von allen diesen Arten wirklicher Peritonäalzysten glauben wir solche zystische Bildungen unterscheiden zu müssen, welche zwischen Verwachsungen des Peritonaeums nach einem entzündlichen Prozesse entstanden sind, sowie das sog. „Pseudomyxoma peritonaei", welches dem Aussehen nach an Zysten erinnert.

(Retroperitonäale Zystenbildungen berücksichtigen wir hier nicht. Auch der weiter unten folgende Fall verdient erwähnt $\mathrm{zu}$ werden, weil er keinem der oben angedeuteten Fälle entspricht.)

Was die makroskopischen Eigenschaften anbetrifft, so besteht wohl zwischen den oben genannten Zystenarten kein prinzipieller Unterschied, denn all die Fälle wiesen Zysten von sehr verschiedener Größe und verschiedener Lokalisation auf; nur der Inhalt des sog. Pseudomyxoma weist zuweilen einen Unterschied von dem anderer Zystenarten auf, und auch das nicht immer.

Die oben angeführte Einteilung ist natürlich nicht vollkommen befriedigend, da sie nicht alle Arten, welche möglich wären, erschöpft, und auch die Grenzen zwischen einigen von ihnen, wie z. B. zwischen dem zystischen Lymphangiom und Lymphangioendotheliom können wohl nicht als genügend scharf betrachtet werden. Die beiden letzteren Formen sind schwer voneinander $\mathrm{zu}$ trennen; den in der Literatur beschriebenen Fällen nach scheinen sie nicht selten miteinander kombiniert aufzutreten. Ebenso schwer ist es, eine genaue Grenze zwischen Lymphzysten und Lymphangiomen zu ziehen, da es doch unmöglich ist, immer sicher $z u$ entscheiden, wo man es mit einer Ausdehnung der Lymphgefäße allein, wo dagegen mit einer ansetzenden Geschwulstwucherung zu tun hat.

Trotz aller Nachteile dieser Klassifizierung müssen wir dieselbe in Ermangelung einer besseren beibelialten und uns 
ihrer als Ausgangspunkt bedienen, denn nur durch Vergleichung unseres Falles mit den andern, die schon einen gewissen Namen besitzen und einer der obengenannten Formen entsprechen, können wir die Art und Abstammung unserer Zystenbildung genauer bestimmen. Die sog. Enterokystome entstehen durch Abschnürung eines Teiles der Entodermallamelle des Embryo. Die Wände diesẹ Zysten haben den charakteristischen Bau der Darmwand oder zumindest das charakteristische Epithel desselben.

Eine solche Zyste beschreibt Hedinger ${ }^{2}$ in einem der vier von ihm beobachteten Fälle. Sie entwickelte sich zwischen den Lamellen des Dünndarmgekröses; ihre Wandung war mit mehrschichtigem Plattenepithel ausgekleidet; die Wände selbst bestanden aus zwei zueinander rechtwinklig verlaufenden Muskelfaserschichten, und die Anwesenheit des mehrschichtigen Plattenepithels führte Hedinger zu dem Schluß, die Zyste sei durch Abschnürung eines Teiles des Ösophagus im Embryonalleben entstanden; er bezeichnet sie daher mit dem Namen „Ösophaguszyste".

Es sei erwähnt, daß auch andererseits eine Reihe von "Enterokystomen" beobachtet wurde, die durch Abschnürung: eines Teiles des Ductus omphaloentericus entstanden sinả. (Roth, V. A. Bd. 86, und Runkel, I.-D. 1897, Marburg).

Länger werden wir uns bei den Lymphzysten, zystischen Lymphangiomen und verwandten Gebilden aufhalten müssen, weil sie verhältnismäBig am öftesten im Peritonaeum beobachtet werden, und weil wir viele dieser Beobachtungen in der Literatur beschrieben finden. Auch besitzen sie einige gemeinsame Eigenschaften mit der Zyste, welche wir weiter unten beschreiben wollen.

Anmerkungen über Zysten der Lymphgefäße des Peritonaeums finden sich hier und da schon in der älteren Literatur. ${ }^{5}$ Jedoch erst im Jahre 1875 beschrieb Weichselbaum ${ }^{3}$, wie es scheint als Erster, einen Fall von kavernösem Chylangiom. Bei einem 80jährigen Manne wurde zufällig bei der Obduktion zwischen den Lamellen des Mleumgekröses ein Tumor bemerkt, welcher äußerlich einem Lipome ähnelte. Die nähere Untersuchung ergab, daß der Tumor wirklich größtenteils aus Fett- 
gewobe bestand: in diesem befand sich jedoch eine große $\Lambda n^{-}$ zahl von Kammern verschicdener Größe, die von einer milehigweißen Flüssigkeit ausgefüllt waren. I)ie Wände der einzelnen Kammern waren aus Bindegewebe aufgebaut, das aus stellenweise netzförmig angeordneten Bälkchen bestand und in die benachbarten Räume führende Öffnungen aufwies. Endothel war nur an den Wänden kleinerer Räume in Gestalt flacher, spindelförmiger Zellen sichtbar; die Wandungen der kleinsten Zystchen bestanden ausschlieblich aus Endothel. Im Bindegewebe befand sich eine ziemlich große Menge Farbstoff. In den Randpartien des Tumors befanden sich stellenweise im Fettgewebe erbsengroße Herde, welche im ersten Augenblicke an festes Bindegewebe erinnerten. Mikroskopische Untersuchung solcher Stellen ergab Gruppen kleiner runder Zellen, einem Lymphfollikel ähnlich. In einigen Teilen dieser Follikel fand Weichselbaum ausgedehnte Lymphräume. Eben diese Bilder machten es möglich, die Genese der Neubildung zu bestimmen. Weichselbaum nimmt an, daß diese verbreiterten Lymphräume im Lymphfollikel die primäre Anlage späterer Zystchen sind, und vermatet, $d a ß$ in einem schon früher bestehenden Lipom durch allmähliche Ausdehnung der Eymphgefäße sich ein "Lymphangioma cavernosum" entwickelt hat.

Im Jahre 1882 beschrieb Werth ${ }^{4}$ eine kindskopfgroße Zyste zwischen den Lamellen des Dünndarmgekröses, mit ziemlich dickem, milchig-kreidigem Inhait ausgefüllt. Die Wand der Zyste war stellenweise durchscheinend dünn, aber fest; größtenteils betrug die Dicke der Wand 2 bis $4 \mathrm{~mm}$ und zeigte am Durchschnitt einen balkenförmigen Bau. Die Wandungen waren nirgends mit Epithelzellen ausgekleidet; sie bestanden nur aus Bindegewebe, dessen äußere und innere Schichte fest, die mittlere aber lockerer war. In dieser mittleren, mehr lockeren Schichte befanden sich Lückchen und Spalten mit runden und polygonalen kleinkernigen Zellen verschiedener Größe ausgefüllt; an einigen Stellen dieser Schichte, nicht sehr verbreitet, befand sich lymphatisches Gewebe und endlich vereinzelt zarte Muskelbündel. Mit Ausnahme der äußersten Schichte war die ganze Wand reich mit Blutgefäßen versehen. Auf Grund des mikroskopischen Bildes meint Werth, eine 
Lymphdrüse des Gekröses für den allein möglichen Ausgangspunkt dieses Prozesses halten zu müssen und beruft sich auf die im Rokitanskyschen Handbuch für pathologische Anatomie angegebenen Ansammlungen von verdicktem Chylus ("Infarkte"), bei welchen die Drüsen sich vergrößern und die ableitenden Gefäbe verwachsen. Ansammlungen von Lymphe oder Chylus in den Drüsen führten also zur zystischen Degeneration derselben, zu ihrer Umwandlung in uni- oder multilokuläre Zysten.

In einer Abhandlung von $\mathrm{Hahn}^{6}$ aus dem Jahre 1887 finden wir schon mehrere (11) aus der chirurgischen Literatur gesammelte Fälle von den sog. serösen, in dem Gekröse gelagerten Lymphzysten, angegeben. Als charakteristisches Kennzeichen für diese Zysten betrachtet Hahn - mit Ausnahme des Küsterschen Falles; wo mehrschichtiges Epithel vorhanden war (ein chirurg. Triennium, 1882, Berlin, nach Hahn) - das Fehlen des Endothels. Aus späteren Arbeiten Tilgexs ${ }^{7}$, Lions ${ }^{8}$ u. a. folgt im Gegensatz zu Hahns Anschauung, daß solche Zysten gewöhnlich eine Endothelauskleidung besitzen, wie dies zuerst Heinrichs ${ }^{9}$ nachwies.

Im Jahre 1895 beschrieb Tilger ${ }^{7}$ sehr genau eine Zystenbildung, welche in der Leiche einer 81 jährigen Frau, zwischen beiden Lamellen des kleinen Netzes über der kleinen Magenkrümmung und in den vorderen Teil des Ligamentum hepatoduodenale sich vorwölbend, gefunden wurde. Diese Zyste hatte ungefähr $40 \mathrm{~mm}$ Durchmesser, war beweglich und stand mittels eines Stieles aus verdicktem Subserosagewebe der kleinen Nagenkrümmung mit dem Magen in Verbindung. Die seitlichen freien Teile des Netzes waren teilweise mit der Geschwulst verwachsen und dadurch derselben genähert. In der Zyste fand man etwa $14 \mathrm{ccm}$ einer hellgelben, fettigen Flüssigkeit, in welcher zahlireiche silberglänzende Schüppchen Cholestearinkristalle - schwammen. Die Wand der Zyste war derb faserig, 2 bis $4 \mathrm{~mm}$ dick. Nach unten za merklich dicker, ging sie in das Subserosagewebe des Magens über. Nach Anschneiden der Zyste erschienen ganz unabhängig von der großen und dieser vollkommen ähnlich, kleine, stecknadelkopfgroße Zystchen. An der inneren Fläche standen in ver- 
schiedener Richtang verlaufende Leistchen und Bälkchen hervor. Mikroskopisch bestand die Wand ans faserigem, wenig Zellen enthaltendem, stellenweise hyalinem, sich schlecht färbendem Bindegewebe. Die Bälkchen, welche an der inneren Fläche sichtbar waren, zeigten unter dem Mikroskope einen Bau von auf dem Querschnitte konzentrisch verlaufenden Bindegewebsfasern und enthielten zahlreiche Kalkablagerungen. In der Nähe der inneren Fläche der Zyste fanden sich stellenweise im Fasernetze degenerierte Reste lymphatischen Gewebes. In der Wand sah man spärliche Blutgefäße.

Im Gegensatze zu dem schlecht färbbaren, die eigentliche Wand der Zyste bildenden Bindegewebe färbten sich Zellplasma und Zellkerne des lockeren, den Verbindungsstiel zwischen Zyste und Magen bildenden Bindegewebes sehr lebhaft. Dieses mehr lockere und zellreiche Bindegewebe war von verschieden gestalteten Lücken durchbrochen, welche verbreiterte Lymphräume bildeten. Diese Spalträume waren von länglichen, flach spindeligen, mit großen bläschenförmigen Kernen versehenen Zellen ausgekleidet, welche Auskleidung in einigen Ränmen ein-, in anderen zwei- oder dreischichtig war. Einige besonders kleine Räume waren sogar vollständig mit solchen spindelförmigen Zellen ausgefüllt. In den größeren Spalträumen befanden sich große runde Zellen mit hyalinem, teils körnigem, teils fettig degeneriertem Protoplasma. In solchen runden Zellen findet man nicht selten 2, 3, ja sogar 10 bis 15 Kerne, so daß man einige von ihnen als Riesenzellen ansehen muß. Durch ihre unregelmäßige Lagerung und scharf begrenzte Konturen unterscheiden sich diese Zellen beträchtlich von tuberkulösen Riesenzellen. Tilger wies eine ganze Reihe von Bildern, welche Übergangsstadien der spindelförmigen Zellen in die Riesenzellen darstellen, nach.

Die Anwesenheit der mehrschichtigen Endothelauskleidung in den oben bescbriebenen lymphatischen Spalträumen, die gänzliche Ausfüllung einiger solcher Räume mit Zellen betrachtet Tilger als einen Beweis der Endothelwucherung. Letztere muP nach Tilger als Zeichen einer chronischen Entzündung der Lymphgefäße (Lymphangoitis chronica desquamativa) betrachtet werden, als eine Folge der Verbreitung eines 
möglicherweise chemischen Entzündungserregers auf dem Wege der Lymphgefäße aus einem alten Digestionsgeschwüre, welches in diesem Falle an der kleinen Magenkurvatur vorgefunden wurde. Infolgedessen entstand eine Entzündung der Lymphgefäßwände, eine reichliche Proliferation und Abschuppung des Endothels mit darauf folgendem Verschluß des Gefäßlumens durch die desquamierten Zellen und eine Ausdehnung der Gefäße bis zur Entstehung von wahren Zysten.

Zur Bestätigung seiner Vermutung, daß die Zyste durch die Proliferationsprozesse in den Lymphgefäßen entstanden ist, zitiert Tilger eine Arbeit von Ledderhose ${ }^{10}$, welcher 6 Fälle tranmatischer Lymphzysten der unteren Gliedmaßen mit ähnlichen deutlichen Proliferationserscheinungen des Endothels beschrieb.

Von anderen Arbeiten, welche über ähnliche Zysten handeln, verdient diejenige Lions ${ }^{8}$ einige Aufmerksamkeit. Er beschrieb eine aus der Bauchhöhle eines $3 \frac{1}{2}$ jährigen Mädchens operativ entfernte dünnwandige Zyste, die vom breiten Mutterbande ausging und die ganze Bauchhöhle ausfüllte. Der Inhalt stellte eine $4800 \mathrm{ccm}$ einnehmende, gelbliche, trübe Flüssigkeitsmenge dar, deren chemische Zusammensetzung derjenigen der Lymphe entsprach, was auch die Möglichkeit der Ausschließung einer Ovarialzyste gab, deren Inhalt gewöhnlich Pseudomucin enthält. Die Oberfläche des Tumors war glatt, von der Serosa bedeckt, stellenweise waren an ihr kleine Zystchen sichtbar, welche mit der großen Zyste kommunizierten, was an der Innenfläche zu erkennen war. Die Wand der Zyste bestand aus ziemlich festem Bindegewebe, in welchem verschieden große und verschieden gestaltete Lücken und Räume sich befanden. Alle diese Räume, wie auch die Innenfläche der Zyste waren von einer kontinuierlichen Schicht flacher, länglicher, rundkerniger, endothelialer Zellen ausgekleidet. In einigen Räumen bemerkte man eine zwei- bis dreischichtige Auskleidung aus. solchen Endothelzellen. In dem die Wand darstellenden Bindegewebe fanden sich - besonders in der Nähe der Spalten und Lymphräume - verstreut Herde von kleinzelligen Infiltraten wie auch breite Züge glatter Muskelfasern.

Auf Grund dieses mikroskopischen Bildes bezeichnet Lion seinen Fall als Lymphzyste and bemerkt zugleich, daß wenn 
er sich an Wegners ${ }^{11}$ Einteilung in Lymphangioma simplex cavernosum und cysticum halten wollte, er seinen Fall in beide Kategorien einschalten und Lymphangioma cavernosum cysticum nennen müßte.

Um über die Genese seiner Zyste klar zu werden, stellt; Lion vor allem die Ansichten verschiedener Autoren über die Entstehungsart der Lymphzysten im allgemeinen und der Lymphzysten der Bauchhöle im besonderen zusammen. Den 45 Fällen nach, welche er aus der Literatur sammeln konnte, unterscheidet Lion drei Entstehungsarten der intraund retroperitonäalen Lymphzysten der Bauchhöhle.

1. Durch pathologische Veränderungen im Ductus thoracicus (Verengerung oder Verschließung) sammelt sich die Lymphe in den zuführenden Lymphgefäßen und ruft so deren manchmal zystenartige passive Ausdehnung hervor. Eine solche Deutung geben ihren Fällen Bramann ${ }^{12}$, Winiwarter ${ }^{17}$ und B o ström ${ }^{1+}$. Da jedoch im Lymphgefäßsysteme äußerst leicht Kollateralkreisläufe entstehen und ohnedies der Ductus thoracicus selten einzeln auftritt, sondern im Gegenteil beinahe immer Kollateraläste besitzt, meint Lion, daß diese Entstehungsweise eine sehr seltene ist und eine untergeordnete Rolle spielt.

2. Schon öfter, denn in 11 von den durch Lion gesammelten Fällen wurden Lymphdrüsen nach dem Beispiele Roki tanskys ${ }^{\check{5}}$ und Virchows ${ }^{15}$ als Ausgangspunkt für Peritonäalzysten betrachtet. Ansammlung von Lymphe oder Chylus führt zur zystischen Degeneration der Drüse, zu deren Verwandlung in einen viel- oder einkammerigen dünnwandigen schlaffen oder dickwandigen Sack. Solch eine Metamorphose kann die Folge sein einer Verschließung der abführenden Lymphgefäße (Vasa efferentia), oder von Veränderungen in der Umgebung der Gefäßwandungen, welche wieder ihrerseits eine Erschwerung des Abflusses der Lymphe hervorrufen. Nach Lion könnte man diese Entstehungsart in allen jenen Fällen annehmen, wo in der Zystenwand noch Lymphdrüsengewebe aufzufinden ist.

3. Die dritte Art ist die Entstehung aus kleineren LymphgefäBen (in einem der von Lion gesammelten Fälle in dem von Rask vorzüglich beobachteten, soll die Zyste durch Bersten eines Lymphgefäßes and Ansammlung der Lymphe zwischen 
den Gekröselamellen entstanden sein). Nach Wegner ${ }^{11}$ kann der Prozeß wieder in dreierlei Weise vor sich gehen: a) dureh stufenweise, allmähliche Ausdehnung der Lymphgefäße mit gleichzeitiger stufenweiser Zunahme der Wand (ectasia cum hyperplasia) hervorgerufen durch Lymphstase, b) durch aktive Proliferation des Lymphendothels: inmitten der hierdurch gebildeten Zellherde bilden. sich newe Lymphgefäße durch Verbindung der Gewebsspalten mit bestehenden Gefäßen (homöoplastische Neoplasie); c) inmitten ron Bindegewebe entwickelt sich Granulationsgewebe, in welchem durch sekundäre Umänderung neue Lymphräume entstehen (heteroplastische Neoplasie). Wegner selbst betrachtet die erste, d. h. die Entstehungsart der Lymphangiome aus kleineren Lymphgefäßen, durch Stase als die weitaus häufigste. Diese Ansicht teilt auch Middel$\operatorname{dorpf} f^{16}$, wogegen andere Autoren eine viel geringere oder, wie Langhans ${ }^{17}$, gar keine Bedeutung der Stase zuschreiben, indern sie das Hauptgewicht auf die Neubildung der Lymphgefäße legen. Noch andere, wie z. B. Schwarzenberger ${ }^{18}$, stellen sich die Entstehung dieser Zysten nicht als durch Mitwirkung von Neubildung und Stauung verursacht vor, sondern einfach als Retraktionsvorgänge des benachbarten Narbengewebes in derselben Weise, wie Rindfleisch die Genese der kavernösen Angiome deutete. Allen diesen älteren Anschaungen, die den Lymphgefäßen bei der Entstehung von Zysten eine passive oder auch nur sekundär aktive Rolle zuschreiben, stellt Lion neuere Forschungen in den Arbeiten Tilgers und Ledderhoses entgegen, wo die primäre aktive Mitwirkung der Lymphgefäße in Form einer Endothelwucherung nachgewiesen wurde, und schreibt auch der in seinem Falle beobachteten Wucherung des Endothels eine ähnliche Bedeutung zu. Er schließt jedoch hierbei die Möglichkeit aus, es könnte auch die Retraktion des benachbarten Bindegewebes und selbst (in kleinerem Maße) die in der Zystenwand aufgefundenen zahlreichen Muskelfasern auf die Ausdehnung der Lymphgefäße irgendwelche Einwirkung haben. Schließlich glaubt Lion auf Grund der Jugendlichkeit des Individuums, dem er die Zyste entnahm, und mit Rücksicht auf die Analogie mit den „äußeren" Lymphzysten, dem ganzen Prozesse einen angeborenen Ausgangspunkt zuschreiben zu können. 
Die Arbeit Lions, wie aus dem obigen ersichtlich, ist eine von jenen, wo die Begriffe Lymphzyste und eigentliches Lymphangiom nicht so genau voneinander abgegrenzt wurden, wie es unserer Meinung nach mit Recht die späteren Autoren getan haben. Diese Abgrenzung wurde in der neuesten Zeit· schärfer ausgeführt von Sick ${ }^{39}$, der eine ausführliche Literatur über Lymphzysten und Lymphangiome im allgemeinen aufführt und überdies zwei eigene Fälle beschreibt. Einer von diesen soll nach Sicks Meinung ein eigentliches zystisches Lymphangiom darstellen. Dasselbe ging von dem retroperitonäalen Gewebe aus und wölbte sich nur in das Peritonäum vor. Es bestand aus Zysten versehiedener Größe und Gestalt, durch reiches proliferierendes Bindegewebe voneinander getrennt. Sick bemerkte in vielen Lymphräumen Verschluß derselben durch junges, nach Sicks Meinung durch Organisation der Lymphkoagula entstandenes Bindegewebe, in welchem Lymphgefäße mit darauffolgender Ausdehnung derselben in Zysten entstanden.

Der Autor meint, daß die Entwicklung der Geschwulst am besten die Annahme ,eines im Embryonalleben selbständig gewordenen Lymphgefäß-Bindegewebskeimes mit progressivem Wachstum." erklären würde.

Zugunsten dieser Vermutung spricht die Entstehung wirklicher Lymphknoten in den Wänden der neugebildeten Lymphgefäße, was an die Entstehung des lymphadenoiden Gewebes im Embryo erinnert. Im anderen Falle dagegen, in welchem es sich um multiple Zysten des Ligamentum hepato-duodenale handelte, konnte ihre angiomatöse Natur nicht wie im ersten bewiesen werden. Der Bau dieser Zysten war äußerst einfach. Die Wand bestand ans Bindegewebe mit einer Beimengung glatter Muskelfasern und war von einschichtigem Endothel ausgekleidet; in dem benachbarten lockeren Bindegewebe befanden sich ausgedehnte Lymphgefäße; nirgends konnte ein Wuchern der Bestandteile der Wand and eine Neubildung von Lymphgefäßen bemerkt werden. Dieser Fall würde demnach dem Begriffe einer einfachen, durch Lymphangiektasie entstandenen Lymphzyste entsprechen. Sick selbst stellt diesen. Fall an die Grenze zwischen dem Lymphangiom und der einfachen 
Retentionszyste (Lymphangiektasia), indem er vermutet, daß die Neubildung längere Zeit vor der vorgenommenen Untersuchung zum Stillstand gekommen ist, und daß ihre Spuren sekundär verwischt worden sind. Diesen Standpunkt nimmt Sick mit Rücksicht auf die neueren Anschauungen ein (Ribbert, nach ihm Rister und Smoler, die alle Lymphzysten als Geschwulstprozesse ansehen), und mit Rücksicht darauf, daß in seinem Falle kein Grund zur Stauung nachgewiesen werden konnte. Eine besondere Besprechung verdienen weiter noch einige Fälle von Zysten, welche sich mit eigentümlicher Lokalisation und eigentümlichem makroskopischen Bilde auszeichnen, und welche teilweise als Lymph-, teilweise als eine etwas andere Art von Zysten anzusehen sind. Der Sitz der Zyste war in diesen Fällen (ähnlich wie in dem unseren) das groBe Netz; in dem einen war es das Netz ausschließlich, in den übrigen dagegen befanden sich die Zysten auch an anderen Teilen des Peritonaeums. Es sind dies im allgemeinen seltene Fälle, denn anßer den von Lio n zusammengefaßten Beobachtungen Spen cerWells' (a. a. 0.8) und Schwarzenbergers (a. a. 0.8), die einfache, mit Endothelauskleidung versehene und Muskelfasern in ihrer bindegewebigen Wand enthaltende Lymph- oder Chyluszysten betreffen, fanden wir in der Literatur folgende Beschreibungen von Zysten des großen Netzes.

Ris ${ }^{19}$ beschreibt eine Zyste bei einem 50jährigen Hausierer. Vor einigen Wochen fing der bis dahin gesunde Mann an Erbrechen, Appetitlosigkeit nnd Schweregefühl in der Magengegend zu leiden an, wobei der Kranke sehr abmagerte. - Die äußere Untersuchung ergab bei ihm in der Höhe des Nabels einen kindsfaustgroßen, eiförmigen, harten, leicht verschieblichen Tumor mit unebener Oberfäche. Freie Flüssigkeit in der Bauchhöhle wurde nicht festgestellt. - Die Diagnose war unsicher: ein Karzinom des Magens konnte angesichts der anamnestischen Daten nicht sicher ausgeschlossen werden. Bei der Operation stellte sich heraus, daß der Tumor im großen Netze zwischen dem Magen und dem Colon transversum lag. Er war rund, gespannt, einkammerig, seine Wand war 2-4 mm dick. In einem kleineren Teile $\left(\frac{1}{10}\right)$ war die Oberfläche mit fibrösen, knorpelartigen Ablagerungen bedeckt, und die Wand war hier 7-8 mm dick. Der übrige Teil war fibrös hart. Die Innenfläche der Zyste war stellenweise glatt, stellenweise mit schmalen, in verschiedener Richtung verlaufenden, hervorragenden Fibrillenbündeln bedeckt. Die aus den Netzlamellen herauspräparierte äußere Fläche hatte natürlich ungleichmäßiges Aussehen. An den Stellen, wo sich die oben erwähnten Ablagerungen 
befanden, war sie glatt, beinahe glänzend. Einige Teile waren verkalkt. Der Inhalt bestand aus einer ziemlich dicken, grauroten Masse. - Unter dem Mikroskop fanden sich in ihr Fetttropfen und Blutfarbstoff. - Mikroskopiseh wurden hauptsächlich jene Stellen der Wand untersucht, welche bis zu $4 \mathrm{~mm}$ Dicke gelangten. In der Wand unterschied Ris vier Schichten. Die erste, d.h. die äußere, war dünn und bestand aus dem spindelförmige Zellen enthaltenden Bindegewebe. Diese Schicht ragte mit Falten und Fetzen in das Innere der Zyste. - Blutgefäße spärlich. Nur an einer Stelle, beinahe an der Oberfläche, fand sich ein gröBeres, dickere Wandungen aufweisendes Blutgefäß der Länge nach durchschnitten. Nirgends eine Spur ven Endothel. - Die zweite, etwas dickere Schicht war aus einem in verschiedenen Richtungen durchschnittenen Gewebe zusammengesetzt, welches aus spindelförmigen, mit entsprechenden Kemen versehenen Zellen bestand. Diese Schicht wies große Ähnlichkeit mit glatten Muskelfasern auf und war gefäBreicher als die vorhergehende. In der Umgebung der Gefäße lagen vereinzelte Herde kleinzelliger Infiltrate. - Die dritte Schichit aus lockerem, dünn-fibrillärem Bindegewebe enthielt wenig Zellen, bildete ein Netz von kleineren und größeren Maschen und war gefäßreich. Stellenweise fanden sich auch hier Infiltrate kleiner, runder, einkerniger Zellen, welche sich in der Umgebung von Gefäßen in Gestalt von Lymphknötchen sammelten. - Diese drei Schichten, nicht überall scharf voneinander abgegrenzt, setzten die Hälfte der ganzen Wanddicke zusammen. Die andere Hälfte nahm für sich die vierte äußere Schicht des festen, aus langen, kernarmen Fibrillen bestehenden Bindegewebes ein. Die Fasern dieser änBeren Schicht verliefen in allen Richtungen, der Schnitt jedoch traf meistens Längs- und Querfasern. Wie die innere Schicht, besitzt anch diese nur sehr spärliche Gefäße und wenig kleinzellige Infiltrate. - Die an einer Stelle des Tumors sich befindenden knorpelharten Ablagertungen bestanden aus sehr festem, faserigem Bindegewebe. - Endlich an gewissen Stellen, auf welche Ris durch Ribbert aufmerksam gemacht wurde, wo die Wand glatter, weicher und intensiv gelbbraun gefärbt war, wurden unter dem Mikroskop zwei Schichten gefunden: die äußere von faserigem, die innere von Granulationsgewebe, in welchem tafelförmige Cholestearinkristalle verstreut waren, aufgebant. Um diese Kriställchen befanden sich Riesenzellen, in deren Plasma man eigentümliche sternförmige, nicht fürbbare Gebilde sehen konnte. Ris betrachtet sie als Teile eines nicht näher zn beschreibenden Pilzes.

Das mikroskopische Bild gestattet nach Ris keine bestimmte Diagnose iiber die Natur der Zyste. Am meisten noch erinnert sie $R$ is an die von Virchow ${ }^{20}$ und Grawitz ${ }^{21}$ beschriebenen Zysten, welche ihre Entstehung auf chronische Entzündungsprozesse zurückführen.

Bergmann ${ }^{22}$ gibt folgenden Fall an:

Bei einem 50jährigen Manne trat vor einem Jahre und acht Monaten als erstes Zeichen eine Vorwölbung in der Magengegend hervor - damals wurde ein Magenkatarrh diagnostiziert. Schmerz, Erbrechen und Gelbsucht. 
war nicht vorhanden. Nach einer gewissen Zeit fing der Bauch an, bedeutend zu wachsen; mittels Punktion wurde eine Flüssigkeit entfernt, welche sich jedoch von neuem ansammelte, so daß noch zweimal zur Punktion geschritten werden mußte; das erste Mal wurden $0000 \mathrm{ccm}$, das zweite Mal $1400 \mathrm{ccm}$ blutig gefärbter Flüssigkeit entfernt. - Schließlich schritt man trotz ungewisser Diagnose zur Laparotomie. - Nach Eröffnung der Bauchhöhle zeigte sich eine große, freibewegliche Zyste, welche nur mit ihrem oberen Teile an den Magen angewachsen war, so daß nach Auslassen der Flüssigkeit die Exstirpation nur mit einem Teile der Magenwand (Pylorusgegend) möglich war. Die Zyste war multilokulär, einem Ovarialkystom ähnlich. Im ganzen enthielt sie 9 Liter durchsichtiger, dunkelgelber, in der vorderen Kammer mit Blut gemischter Flüssigkeit; wahrscheinlich wurden bei der Punktion Blutgefäße verletzt. - Die Wand war im allgemeinen dünn, aber fest, und hatte nur im oberen Teile der Zyste ein anderes Aussehen; sie war nämlich an dieser etwa handtellergroßen Stelle viel dicker (etwa 1 Zoll), an dem. Durchschnitte braunrot. Die Mitte dieses Teiles war so fest mit dem Magen verwachsen, daB die Grenzen zwischen dem Peritonaeum des Magens und dem Tumor vollständig verwischt waren. Die Schleimhaut des Magens war normal. - Mikroskopisch wurde nur der verdickte Teil untersucht; in der Arbeit Bergmanns fehlt jedoch die genauere Beschreibung der Resultate dieser Untersuchung; man findet nur eine allgemeine Bestimmung des Falles, als: multilokuläre Zyste des Netzes, welche im oberen Teile einer bösartigen Degeneration - Endothelioma carcinomatosum -- eriag.

Zwei andere Fälle betreffen Zysten, welche außer am Netze noch an anderen Stellen des Peritonaeums anzutreffen waren.

Znfälligerweise fand Henke $\mathrm{H}^{23}$ bei der Autopsie eines 50jährigen: Mannes an den verschiedenen Stellen des Peritonaeums eine Menge dünnwandiger, runder oder länglicher, bläschenförmiger Gebilde von Stecknadelkopf- bis Walnußgröße. Sie waren gröBtenteils gruppenweise traubenförmig angeordnet. Der lnhalt war serös-gallertig. Die meisten Zysten befanủen sich am großen Netze und an der Bursa omentalis. Die an anderen Stellen des Peritonaeums lokalisierten Zysten drangen nirgends tiefer in das Gewebe.

Mikroskopische Untersuchung dieser Gebilde zeigte sie als aus einem Bindegewebsring mit spärlichen Kernen und stellenweise glatten Mnskelfasern bestehend. Innen waren sie von kubischem, stellenweise in zylindrisches übergehendem Epithel ausgekleidet. In dem amorphen Inhalte Koonten nur spärliche Leukocyten und desquamiertes Epithel gefunden. werden.

Nachdem Henke alle anderen Zystenarten, wie Chyluszysten, sog. Pseudomyxoma peritonaei und ähnliche, durch den Vergleich mit den bis dahin bekannten Beobachtungen ausgeschlossen hatte, gelangte er zu dem Sehlusse, es könne hier nur von einem Entsteben der Zysten entweder aus den Lymphgefäßen (lymphangiom) oder durch Abschnürangen des 
Epithels oder Endothels des Peritonaeums nach der Ribbertschen Darstellung (Renggli-Dissert.) ${ }^{24}$ der Milzkapselzysten gesprochen werden. Das Entstehen der Zysten infolge von Entzündungsprozessen schließt Henke dagegen vollständig aus, da keine Zeichen auf das Bestehen solcher Prozesse hindeuten. Wahrscheinlich handelte es sich nach Henke um einen angeborenen Zustand.

Nager ${ }^{25}$ beschrieb im Jahre 1903 den folgenden, mit Rücksicht auf die Diagnose einzig und allein dastehenden Fall.

Bei einem sonst gesunden, erblich nicht belasteten Manne entwickelte sich im Laufe von 10 Jahren in der Bauchhöhle ein Tumor, welcher sich in der letzten Zeit bedeutend vergrößerte, jedoch nicht die den bösartigen Geschwülsten eigentümliche Kachexie hervorrief.

Bei der Laparotomie stieß man gleich nach der Durchtrennung der Bauchdecken auf gallertige Massen, welche überall der vorderen Bauchwand anhafteten, so dab man sie nicht von ihr trennen und ans der Bauchhöhle entfernen konnte. Infolgedessen mußte von der Exstirpation des Tumors abgesehen werden. Einen Monat nach der Laparotomie trat der Tod infolge einer Embolie der Lungenarterie ein. - Die postmortale Untersuchung ergab eine zystische Geschwulst, welche das ganze parietale und viszerale Blatt des Peritonaeums mit Ausnahme des die Gedärme bedeckenden Teiles desselben einnahm. Dieses letztere war nicht in der ganzen Ausdehnung geschwulstartig verändert; an manchen Stellen war die Serosa der Gedärme glatt. Alle Organe der Bauchhöhle waren miteinander und mit der Bauchwand verwachsen. - Den Inhalt der Zyste stellten gallertartige, durchsichtige, zitronenfarbene oder farblose Massen dar. - Der Beschreibung nach könnte es scheinen, daß diese Massen sich auch in der Bauchhöhle selbst befanden, durch Verwachsungen in kleinere zystische Gebilde geteilt.

Auf Grund der mikroskopischen Untersuchung kommt Nager jedoch zu dem Schlusse, daß diese gallertartigen Massen sich nicht in der Peritonäalhöhle selbst befanden, sondern immer in Zysten, welche in dem Gewebe des Peritonaeums selbst dicht unter den Belegzellen desselben lokalisiert wurden. - Die chemische Untersuchung des gallertartigen Inhalts sprach mit Wahrscheinlichkeit für verdickte Lymphe.

An mikroskopischen Präparaten überzengte sich Nager, daß die Zystchen durch Bindegewebsbrücken voneinander getrennt wurden und nur stellenweise miteinander kommunizierten, nirgends aber in die Tiefe des benachbarten. Gewebes eindrangen; so z. B. reichten sie in der Wand des Magens bis zur Muskelschicht, nirgends aber wurde dieselbe ïberschritten. Die Zysten waren meistens rund und nur stellenweise unregelmäßig gestaltet. Der Inhalt, mit Hämatoxylin gefärbt, war blau oder violett, doch nicht ganz gleichmäßig: man sieht nämlich in ihm dunklere, wellige, dünne Linien, teilweise parallel, teilweise senkrecht zur Wand verlaufend. In dem Inhalt einer der Zysten fanden sich polygonale, den mittelgroßen Epithelzellen ähnliche, teilweise mit gut färbbaren Kernen 
aus Plasma versehene, teilweise schlechter färbbare Zellen. Die epithelartigen Zellen lagen bald einzeln, bald gruppenweise. In solehen Gruppen waren die Konturen der Zellen öfters verwischt, wodurch das Bild einer scheinbaren Riesenzelle entstand. Stellenweise ordneten sich die im Lumen einer Zyste liegenden Zellen bandartig an. Eine genauere Untersuchung ergab, daß diese Zellen abgeschiedene Teile der Zystenauskleidung waren. Diese Auskleidung war nicht überall erhalten, stellenweise fehlte sie. Sie bestand aus sehr verschiedenen Zellen; hier und da sah man platte Zellen. mit runden oder länglichen Kernen, an anderen Stellen kubische, an wieder anderen hohe zylindrische. An vielen Stellen fand Nager Zellen, welche Übergangsformen von einer Zellart zu der anderen bildeten: von platten zu kubischen und von kubischen zu zylindrischen. An manchen Stellen bedeckten die Zellen die Wand in mehreren Schichten. Eine solche mehrschichtige Auskleidung bestand immer aus platten Zellen; zylindrische Zellen bildeten darin immer nur eine Schicht. Die Scheidewände zwischen den Zysten bestanden aus Bindegewebe, welches einmal faserig und zell-. arm, das andere Mal zell- und gefäßreicher war. Außer Blutgefäßen befinden sich in den Septen zahlreiche Lymphgefäße und Lymphräume. Die Vergleichung der Bilder verschiedener Schnitte gestattete Nager, Übergänge der Lymphspalten in größere Lymphräume und dieser wieder in. Zysten zu finden. Zwischen diesen Ubergangsbildern fand Nager z. B. solche Spalten, welche teilweise nur mit gallertartiger Masse gefüllt waren, andere wieder, deren Wand teilweise mit einschichtiger, teilweise mit mehrschichtiger Zellage ausgekleidet war, gerade so, wie dies der Fall war bei den einzelnen Zysten. Manchmal wieder waren die Spalten vollständig mit polygonalen Zellen ausgefüllt, vollkommen ähnlich denen, welche im Innern der Zyste inmitten der gallertigen Massen gefunden worden waren. Muskelfaserschichten wurden in der Wand der Zyste nicht gefunden.

Indem Nager die verschiedenen Arten von Zystenbildungen des Peritonaeums durchgeht und ihre Eigenschaften mit denen seiner Zyste vergleicht, schließt er in seinem Falle sogleich Echinokokkus und Enterozystis aus (obzwar er zylindrische Zellen fand, waren keine Becherzellen und Muskelfaserschichten vorhanden). Mit Rücksicht auf des anatomische und klinische Bild kann nach der Meinung von $\mathrm{Nager}$ sein Fall auch nicht Krebsbildungen zugezählt werden. Es fehlten nämlich alle Zeichen der Bösartigkeit (wie Vernichtung der benachbarten Gewebe, Metastasen in entlegenen Organen, Kachexie), und die histologische Untersuchung stellte zweifellos die Verwandtschaft der Zellauskleidung der Zyste mit Endothel fest. Nager schließt anch die gewöhnlichen Lymphzysten aus, in welchen die Auskleidung gewöhnlich von platten Lymphendothel gebildet wird, oder in denen überhaupt kein Endothel gefunden wird und denen selten Muskelfasern fehlen. - - Alle andern Arten von Zysten ausschließend, bezeichnet $\mathrm{Nag}$ er seinen Fall als Lymphangioendothelioma cysticum, und wäre dies der erste bekannte Fall einer solchen Geschwulst des Peritonaeums. 
Es muß bemerkt werden, daß Merkel ${ }^{26}$ diese Diagnose Nagers als nicht richtig bezeichnet, denn er meint, dab der Fall Nagers eher an das sog. von Werth ${ }^{27}$ beschriebene "Pseudomyxoma peritonaei" erinnere, welches durch Erguß des gallertigen Inhalts geborstener Ovarialzysten in die Bauchhöble entsteht. Da der Fall Nagers einen Mann betrifft, vermutet Merkel als primären Prozeß das Bersten eines sog: "Hydrops spurius" des Wurmfortsatzes, wie in dem von Fraenke128 beschriebenen Falle, in welchem der gallertige Inhalt der Bauchhöhle aus dem veränderten Processus vermiformis seinen Ursprung nahm. Wir können hier nicht erörtern, inwiefern die Einwürfe Merkels berechtigt sind: es muß aber einerseits bemerkt werden, daß die chemische Untersuchung des Iuhaltes der Nagerschen Zyste kein Mucin und Pseudomucin nachwies, und dab andererseits die Beschreibung des Wurmfortsatzes gänzlich fehlt. Wir können jedoch nicht umhin, diesen Gegenstand zu berïhren, und zwar aus folgendem Grunde.

Die $\mathrm{Nagersche}$ Diagnose führt in die Literatur eine neue Form von Peritonäalzysten ein, welche von nun an bei der Bestimmung von Zysten des Peritonaeums berücksichtigt werden muß.

Wegen einer gewissen Ähnlichkeit des Falles Nagers mit Pseudomyxoma peritonaei darf in keinem Falle von Peritonäalzyste der erwähnte krankhafte Prozeß vergessen werden. Hier wollen wir nur erwähnen, daß das "Pseudomyxoma peritonaei" nach Ansicht von Werth durch Erguß des gallertigen Inhaltes einer geborstenen Ovarialzyste in das Cavum peritonaei entsteht, wobei sich durch Reizung des Bauchfells bindegewebige Verwachsungen bilden, welche die gallertartige Masse in einzelne Klümpchen teilen, wodurch das Bild zystenartiger, zwischen den Verwachsungen gelegener, mit gallertiger Masse ausgefüllter Räume entstehen kann.

Mit dieser Ansicht stimmen einige Autoren, wie Rueder ${ }^{29}$ und Kretschmer ${ }^{30}$, überein, andere wieder, wie 01 s hausen ${ }^{31}$ und P fannenstiel ${ }^{\text {g2 }}$, betrachten solche Fälle als die Folge von Metastasen einer Ovarialgeschwulst in das Peritonaeum. Die dritten nehmen in gewissen Fällen die erste, in andern die zweite Entstehungsweise an.

In dem oben angeführten, von Fraenkel beschriebenen Falle, in welchem die gallertigen Massen in der Bauchhöhle nicht von einer Ovarialzyste stammten, sondern aus dem Wurmfortsatze, welcher mit ihnen angefüllt war, waren Verwachsungen des Peritonaeums nicht vorhanden; es befanden sich an ihm nur zottenförmige, bindegewebige Fortsätze, welche nicht in die Tiefe der gallertigen Massen wuchsen.

Die letzte, mit Rücksicht auf unseren Fall interessante Peritonäalzystenart ist jene, welche mit Flimmerepithel ausgekleidet ist. Wir begegnen ihr an dem die Gebärmutter und Eileiter umgebenden Peritonaeum an der Oberfläche der Eierstöcke; Pick ${ }^{33}$ fand außerdem eine solche Zyste an dem parietalen Blatte des das kleine Becken auskleidenden Peri- 
tonaeum. Es sind dies kleine, höchstens erbsengroße, einzeln verstrente Zystchen. Das sie auskleidende Flimmerepithel ist hochzylindrisch. Die Abstammung dieses Epithels wurde ron im embryonalen Leben versprengten Teilen der Urniere, des Wolff schen Ganges, von abgeschnürten Teilen des Keimepithels usw. abgeleitet. Pick jedoch meint, daß diese Zellen eine Folge von Metaplasie der gewöhnlichen platten Belegzellen des Peritonaeums in ein zylindrisches Flimmerepithel sind; das behauptet er nicht nur von den obengenannten kleinen Zysten des Peritonaeums, sondern auch von größeren, Flimmerepithel besitzenden Ovarialzysten.

Der Fall, welchen wir zu beschreiben beabsichtigen, ist folgender: Bei einer 38jähr. Frau ist zufällig bei der Autopsie eine zystenartige Geschwulst gefunden worden.

Anatomische Diagnose ergibt folgendes: Pyaemia (cryptogenetica), abscessus multiplices pulmonum praecipue sinistri, renis utriusque, glandulae suprarenalis sinistrae, myocardii, telae subcutaneae. Plenritis purulenta sinistra e. compressione lobi inferioris pulmonis sinistri. Atrophia fusca myocardii. Cicatrices intestini crassi post enteritidem follicularem, enteritis catarrhalis. Tumor cysticus (lymphangioma?) omenti majoris.

Dem Sektionsprotokolle entnehmen wir folgende rus näher angehende Daten:

Die Bauchhöhle leer.

Bauchfell. Der obere Teil des rechten Randes des großen Netzes mit der oberen Hälfte des Colon ascendens verwachsen. In der Nachbarschaft der Flexura coli hepatica ist das Netz normal dünn und locker; $2 \mathrm{~cm}$ unter der Flexur fängt die Randpartie des Netzes an, nach unten dicker zu werden, und man bemerkt an ihm in der Tiefe liegende Zystchen (s. Textfig. 1).

Noch weiter unten werden diese Zysten zahlreicher, liegen dicht nebeneinander, ein tranbenförmiges, ans dünnwandigen, stecknadelkopfbis walnußgroßen Bläschen bestehendes Gebilde darstellend.

Das ganze Gebilde ist faustgrob, im oberen Teile mit dem rechten Rande des Colon transversum, nämlich mit seinem serösen Uberzuge, verwachsen. Die Wand des Darmes bietet an dieser Stelle sonst keine Veränderungen dar.

Nach unten zu hängen an diesem Gebilde 10-20 mit kürzeren und längeren Stielen versehene Bläschen.

Die Zysten, aus welchen dieses Gebilde besteht, sind von verschiedenex Größe, in seinem oberen Teile liegen sie dicht aneinander, nach unten zu hängen sie einzeln und frei.

Thre Wand ist dünn, der Inhalt flüssig, hellgelb und durchsichtig. 
Man bemerkt nirgends Fettgewebe.

Das ganze traubenförmige Gebilde nimmt den rechten Teil des großen Netzes mit Ausnahme des der Flexura coli hepatica angrenzenden Abschnittes ein, erinnert durch sein Aussehen, namentlich durch die gestielten Zystchen, an einen Traubenast.

Der Rest des großen Netzes zeigt keine Veränderungen.

Das Peritonaeum der Gedärme ebenfalls normal und ohne Zysten.

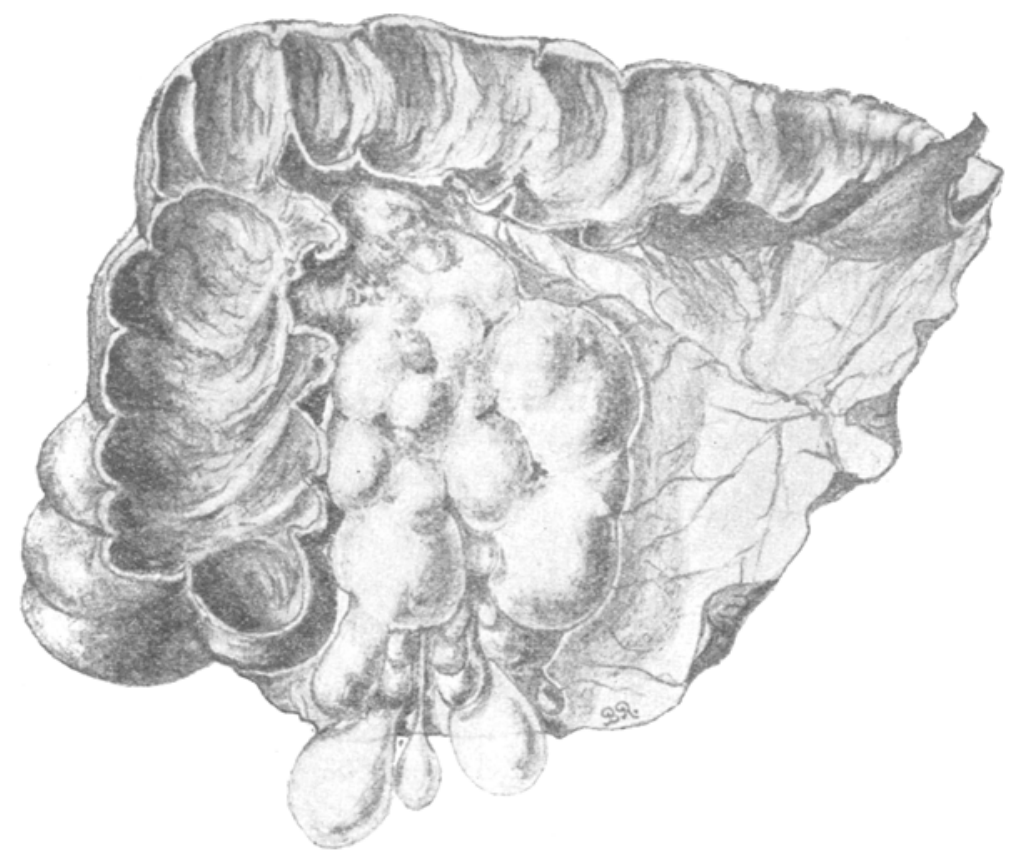

Fig. 1.

Makroskopische Abbildung der multilokulären Zyste.

Metastasen sind nicht nachgewiesen.

Die Milz zweimal vergrößert, ihre Kapsel glatt, das Parenchym ist von rosa Farbe und brüchiger als normal.

Die Bauchspeicheldrüse nicht verändert.

Die Leber von normaler Größe und Gestalt, ihre Kapsel dünn, glatt. Das Parenchym schmutzig rotbraun, ziemlich derb. Die lobuläre Zeichnung erhalten.

Gallenapparat ohne Veränderungen.

Speiseröhre, Magen und Dünndarm normal.

Der Dickdarm enthält dünnflüssige, gelbliche Kotmassen, seine Schleimhaut ödematös und etwas hyperämisch; im Colon transversum, 
descendens und $S$ romanum spärlich verstreute, dünne, rundliche, glatte, graugefärbte Narben.

Der Wurmfortsatz zeigt keine Veränderungen.

Von den Mesenterialdrüsen ist eine in der Nachbarschaft des Coecum und am Ende des Ileum verkalkt, die andere ohne Veränderungen.

Die Gefäßie der Bauchhöhle normal.

Die Harnblase, mäßig erweitert, enthält trüben Harn; ihre Schleimhaut und die der Harnleiter ödematös und hyperämisch.

Die Genitalorgane, die Eileiter im besonderen, zeigen keine Veränderungen.

Zur mikroskopischen Untersuchung wurden aus der Hauptmasse des Tumors Stückchen, kleinere und größere Zystchen enthaltend, ein Bündel kleinster Zystchen an gemeinsamem Stiele sowie auch ein Stïck aus dem oberen Teile des Netzes, wo es schon verdickt ist und sich in der Tiefe Zysten befinden, herausgeschnitten.

Die Präparate wurden in Zelloidin und teilweise in Paraffin eingebettet. Gefärbt wurden die Schnitte hauptsächlich mit Hämatoxylin and Eosin. Es kam auch die Färbung nach van Gieson und die Unna-Tänzersche Elastinfaserfärbung in Anwendung.

Die mikroskopischen Bilder waren nicht überall gleich.

Die Wand der größeren Zysten bestand aus drei Schichten, d. i. einer einschichtigen zelligen Auskleidung und zwei Bindegewebsschichten. Die Zellauskleidung, welche nicht an allen Stellen zu finden ist, besteht aus Zellen, welche nicht überall gleich sịnd. Es überwiegen platte, längliche mit länglichen, großen Kernen versehene, an Endothel erinnernde Zellen. Die Färbbarkeit ist nicht bei allen die gleiche, gröBtenteils färben sich die Kerne intensiv mit Hämatoxylin, in anderen Zellen jedoch sind die Kerne schwach und nur am Rande tingiert, in der Mitte einen untingierten, vakuolenförmigen Kreis bildend.

Das Protoplasma ist auch nicht überall gleich färbbar.

Stellenweise begegnet man in einer solchen Zelle mehr als einem Kern. Außer diesen Zellen findet man an der Innenfläche der Zystenwand größere aufgequollene, an Epithel erinnernde, nicht kubische, sondern halbkugelige, mit der Konvexität dem Lumen der Zyste, mit der abgeflachten Seite der Wand zugewendete und ihr anhaftende Zellen mit einem relativ kleineren, beinahe immer gut tingierbaren Kerne.

AuBerdem finden sich Ubergangsformen von ganz platten zu diesen größeren Zellen, und es kommt vor, daß man in einer Reihe platter eine, zwei, manchmal aueh mehr ins Lumen ragende Zellen findet. Auch diese. Zellen besitzen hier und da zwei Kerne.

An einzelnen Zellen sind Degenerationsprozesse $z a$ bemerken, es sind einige Kerne schlecht tingiert, und in dem Protoplasma der gröferen machen sich Vakuolen bemerkbar. Sie sind kleiner oder größer, nehmen 
manchmal den größeren Teil der Zelle ein und scheinen keinen Inhalt zu haben. Der Kern ist in solchen Zellen an den Rand gedrängt, in einzelnen Fällen nicht sichtbar.

Eine Zellauskleidung ist nicht längs der ganzen Wand erhalten: stellenweise fehlt sie gänzlich, wie wenn sie von der Wand abgerissen worden wäre; man findet jedoch in den größeren Zysten. und diese sind es, welche wir eben beschreiben, keine abgestoßenen, frei im Lumen liegenden Zellen.

Bei Vergleichung der Zellauskleidung der kleineren Zysten mit jener der größeren finden wir keine prinzipiellen Unterschiede; hier wie dort finden wir platte Zellen und Ubergangsformen von platten zu größeren

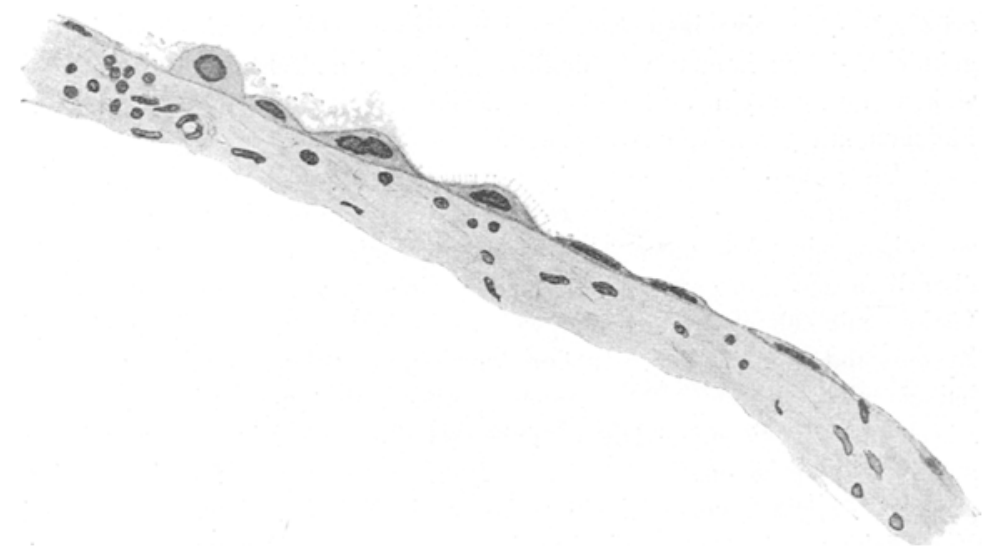

Fig. 2.

Mikroskopisches Bild der Zystenwand mit Flimmerzellen.

aufgequollenen, aber die platte Zellform tritt hier an Zahl in den Vordergrund. Im Lumen der kleinen Zysten findet man hier und da freiliegende, spärliche Zellen. Sie erinnern an Epithel, d. h. an die größere Form der beschriebenen Zellauskleidung der großen Zysten, und sind meistens schlecht tingierbar; in vielen ist der Kern nicht sichtbar.

Diese abgestoßenen Zellen liegen manchmal in Gruppen von vier bis fünf. In den kleineren, meistens, jedoch nicht immer, runden Zysten findet man im Lumen ganze Bänder von der Wand abgestoßener Zellen. Als ganz besonders wichtig betrachten wir eine bis dahin in den Netzzysten, soviel uns bekannt ist, nicht beschriebene Eigenschaft der Zellauskleidung der Zysten. - Gewisse Zellen besitzen nämlich ganz deutlich sichtbare, winzige Härchen, welche den ganzen freien Rand einer oder mehrerer benachbarter Zellen bedecken. - Nicht in allen Präparaten sind sie dentlich sichtbar, es sind stellenweise nur Reste und Schatten solcher Härchen zu bemerken (s. Textfig. 2 u. 3). 
An Stellen, wo diese Härchen deutlich zu sehen sind, bilden sie zarte, vertikal zur Oberfläche der Zelle gestellte Fäden und sind an flachen Zellen aufrecht aneinandergereiht, an den größeren, halbkugeligen Zellen sind sie strahlenförmig angeordnet. - Die Färbbarkeit der Härchen ist gering. - In mit Hämatoxylin überfärbten Präparaten stellen sie sich violett dar; an schwächer gefärbten Präparaten sind sie ganz blaß und nur auf Grund des verschiedenen Brechungsindex von dex Umgebung zu unterscheiden.

In Präparaten, welche nach der van Giesonschen Methode behandelt wurden, konnten wir sie nicht nachweisen.

Diese Fädchen sind nicht überall gleich lang. Ihre Länge ist gewöhnlich der Höhe der Zelle gleich, ist aber in manchen Fällen auch größer. - An einzelnen Zellen sind diese Fädchen wie gedreht oder geknickt. - Es kommt vor, daß einige dieser gedrehten Fädchen isoliert stehen, und an ein und derselben Zelle findet man stellenweise gerade Fädchen mit geknickten zusammen.

Die gröBeren Zellen besitzen ebenso wie die ganz platten solche Härchen.

Betrachten wir jetzt die zwei anderen Schichten der größeren Zysten, so sehen wir, daß diese Teilung in zwei abgesonderte Schichten nicht überall durchzuführen ist: es befinden sich zwischen ihnen stellenweise Lücken mit Zellen ausgekleidet, welche denjenigen an der Innenfläche der Zystenwand ähnlich sind. In der Auskleidung solcher Lücken finden wir jedoch nicht jene größeren Zellen und konnten auch nicht solche mit Härchen nachweisen. - Diese Lücken machen den Eindruck von Lymphspalten. Beide obengenannten Schichten bestehen aus faserigem Binde-. gewebe. - Die innere Schicht weist wenig Zellen und wenig Gefäße im Vergleiche zur äußeren auf. Die letztere ist an Zellen und Gefäßen viel reicher.

Stellenweise sind in dem faserigen Bindegewebe kleine runde Zellen in geringer Anzahl nachznweisen. In einigen Präparaten zeigt die faserige Wand der Zyste an einer Stelle eine Verdickung, welche einen Gewebsherd darstellt, dessen spärliche Zellen in einer bläulich tingierbaren interzellularen Substanz verteilt sind; man könnte geneigt sein, ihn für einen hyalin degenerierten Herd $z \mathbf{u}$ halten. Solche Herde sind auch in den Wänden kleinerer Zysten zu finden, worauf wir jedoch später noch zurückkommen.

Die äußere Schicht besteht ebenfalls aus Bindegewebsfasern, ist aber zell- und gefäßreicher als die innere, und wir begegnen in ihr kleinrundzelligen Infiltrationen. Diese erinnern nirgends an Lymphknötchen, da ihnen die gleichmäßige Form und der charakteristische Bau derselben fehlt. Die Infiltrationen sind an verschiedenen Stellen zu finden, und wir konnten nicht irgendeine spezielle Lokalisation, wie in der Umgebung von Gefäßen oder nahe der Zystenoberfäche, nachweisen.

Die Blutgefäße sind stellenweise ganz beträchtlich dilatiert und mit roten Blutkörperchen gefüllt. 
Was die kleinen Zysten anbetrifft, so läßt sich ihre Wand nicht deutlich in zwei Schichten teilen. Die Scheidewände zwischen kleinen Zysten bestehen aus einem überwiegend zelligen Gewebe, welches Ähnlichkeit mit Granulationsgewebe aufweist und mit kleinen Rundzellen infiltriert ist. An manchen Stellen dieses Bindegewebes finden wir ähnliche Herde wie in der Wand der größeren Zysten, welche auch hyalin degeneriert erscheinen. - Die äußere, dem Peritonaeum zugewandte Zystenfläche weist gewöhnlich keine endotheliale Auskleidung auf.

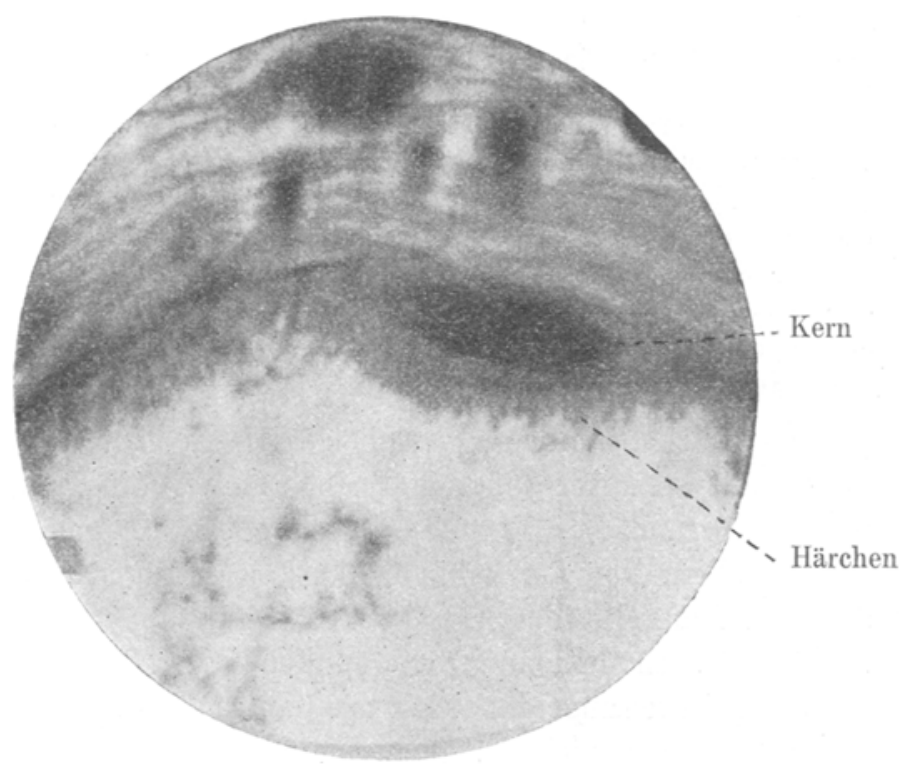

Fig. 3.

Mikrophotographie einer Flimmerzelle der Zystenwand.

Die Präparate ans dem oberen Teile des Netzes über dem Tumor, wo die Zysten sich nur in der Tiefe befanden, wiesen folgendes Bild auf: Den einen Rand des Präparates bildet das von Endothel entblöBte und aus einer dünnen Schicht ziemlich festen Bindegewebes bestehende Peritonaeum; der gegenüberliegende Rand ist die gefäßreiche Wand einer größeren Zyste, welche aus festem, faserigem Bindegewebe gebildet und nit einer den anderen Zysten ähnlichen Zellauskleidung versehen ist. In der Wand derselben machen sich in einigen Präparaten kleine rundliche Zystchen bemerkbar, welche überall mit einer einschichtigen Zellauskleidnng versehen sind. Dieselbe besteht ans teils platten, teils halbrundlichen, stellenweise mit den schon beschriebenen Härchen versehenen Zellen. - Die Mittelpartie des Präparates zwischen beiden 
Rändern - einerseits Peritonaeum, andererseits Zystenwand - besteht aus einem lockeren, reich von Gefäßen und Lymphspalten durchsetzten Bindegewebe. - Die Spalten sind überall von einschichtigem, plattem Endothel ausgekleidet. Um die GefäBe herum finden sich Zellherde mit größtenteils runden Zellen von blassem, einheitlichem Protoplasma und mit ziemlich blaß tingierbaren, runden Kernen; neben diesen finden wil in den Herden weniger zahlreiche, kleine Zellen, mit kleinen, runden, intensiv mit Hämatoxylin gefärbten Kernen und schlieBlich hier und da Zellen von unregelmäßiger Gestalt, mit zur Seite gedrängtem Kerne und dunkler tingiertem Protoplasma; diese Zellen exinnern lebhaft an Plasmazellen.

Nirgends ist der Übergang einer Lymphspalte in eine Zyste und auch keine Spuren einer Proliferation des Endothels nachzuweisen.

In keinem der untersuchten Teile des Tumors fanden wir in der Zystenwand Muskelfasern.

Nirgends fanden wir, außer in der Umgebung von größeren Gefäßen, elastische Fasern.

Schließlich bemerken wir, daß wir in keiner Zyste einer aus zylindrischen oder kubischen Zellen bestehenden Auskleidung begegneten und die vorgefandenen Flimmerzellen sich ganz bedeutend von dem typischen. Flimmerepithel unterscheiden.

Es ist $\mathrm{zu}$ bestimmen, welcher von den oben angeführten Peritonäalzystenarten unser Fall angereiht werden kann.

Auf Grund der Resultate unserer Untersuchung können wir vor allem (von der Echinokokkuskapsel gar nicht zu reden) das sog. Enterokystom ausschließen, weil die für diese Fälle charakteristisch hohen Zylinderepithelien und die bekanntlich in zwei Schichten angeordneten Muskelfasern nicht vorhanden sind.

Es ist auch nicht möglich, irgendwelche Ähnlichkeit mit. dem von Werth beschriebenen sog. Pseudomyxoma peritonaei nachzuweisen, schon aus dem Grunde, daß Eierstöcke und Wurmfortsatz vollständig normal waren.

Es ist auch das makroskopische Bild unseres Falles von dem Werths vollkommen verschieden. In unserem Falle ist der Prozeß ganz genau an einen begrenzten Raum des Peritonaeums lokalisiert, während er im Falle Werths und anderen ähnlichen infolge des Berstens der Ovarialzyste auf das ganze parietale und viszerale Peritonaeum übertragen wurde.

Was schließlich die Lymphzysten, Retentionslymphzysten, wie auch zystische Lymphangiome und Lymphangioendotheliome anbetrifft, so können wir auch diese mit aller Wahrscheinlichkeit ausschließen, denn, obzwar wir in dem Bilde 
aus den oberen Teilen des Netzes über dem eigentlichen zystischen Tumor dilatierte Lymphspalten fanden, so konnten wir doch nirgends zwischen ihnen und den eigentlichen Zysten irgendeinen Zusammenhang nachweisen.

Auch war nirgends eine sichtbare Proliferation der Endothelien zu finden, wie sie in allen Fällen beschrieben wurde, welche mit einigem Rechte in die zystenartigen Lymphangioendotheliome eingereiht wurden oder hätten eingereiht werden können, nirgends fanden wir schließlieh Muskelfasern, wie sie bei Retentionslymphzysten, wie auch zystenartigen Lymphangiomen oft $z \mathfrak{z}$ finden sind.

Wir betrachten indessen als wichtige Tatsache zur Erklärung der Genese unseres Falles die Anwesenheit von Flimmern an den die Innenfläche der Zyste auskleidenden Zellen. Es ist dies um so interessanter, als diese Flimmerzellen gar nicht denjenigen des eigentlichen Flimmerepithels ähnlich sind, sondern, abgesehen von den Flimmern, den Endothelialzellen, welche gewöhnlich die Lymphräume auskleiden, wie auch den Deckzellen, welche wir an der Oberfläche seröser Häute (seröser Deckzellen), besonders des Bauchfells, finden (heute von den meisten Histologen Serosaepithel benannt).

In der neueren Zeit wurde eben diesen Endothelien oder „serösen“ Epithelien größere Aufmerksamkeit zugewendet und auf Einzelheiten ihres zarteren Baues aufmerksam gemacht.

Im Gegensatze zu der älteren Ansicht, es seien diese Zellen morphologisch im großen und ganzen nur wenig von den Endothelzellen verschieden, behauptete Kolossow ${ }^{34}$, sie seien komplizierter gebaut. Nach Einwirkung mit Osmiumsäure beobachtete er an den Endothelzellen seröser Höhlen zwei Schichten, ein oberflächlicheres, dünnes, homogenes Häutchen und eine tiefere Schicht leicht granulierten Protoplasmas mit einem Kerne und zwei Kernkörperchen. Die Oberfläche des Häutchens war mit einem Saume dichter, durchschnittlich $2 \mu$ langer Härchen bedeckt.

Es hatte zwar schon Palladino 50 vor Kolossow auf diese Härchen aufmerksam gemacht; er betrachtete sie jedoch als rudimentär und zufällig; während es Kolossow gelang; diese Härchen nicht nur bei Säugetieren, sondern auch normaler- 
weise bei Menschen nachzuweisen. Muscatello bestätigte die Beobachtungen Kolossows, fand aber die Härchen nur aach Einwirkung von Osmiumsäure und nie an frischen Präparaten. Von deutschen Autoren wies zuerst Büttner ${ }^{36}$ bei Tieren Härchen an den gequollenen Zellen der Pleura 15. Stunden nach einer Staphylokokkeninjektion in die Pleurahöhle nach.

Anfänglich betrachtete er diese Härchen als ein pathologisehes Produkt, fand sie aber bei späteren Untersuchungen an Zellen, welche keine pathologischen Veränderungen aufwiesen.

Büttner nahm nun an, daß diese Härchen ein ständiger Bestandteil der Zellen seröser Häute bei jungen Meerschweinchen und Kaninchen bilden.

Die späteren Forschungen Brunns ${ }^{36}$ bestätigten die Beobachtungen Kolossows in ihrer ganzen Ausdehnung. Brunn fand diese Härchen an Zellen der seröseu Häute bei Hunden, Menschen, Kaninchen, Meerschweinchen, weißen Mäusen und Tauben. Sie befinden sich an Pleura, an Perikard, an viszeralem und parietalem Bauchfell mit großer RegelmäBigkeit, wenn auch nicht an allen Stellen. Worauf diese letzte Tatsache beruht, kann Brun n nicht entscheiden, macht aber auf die ungemeine Zartheit der Härchen aufmerksam, infolgederen sie durch den geringsten Eingriff vernichtet werden können. Um die Härchen sichtbar zu machen, muß auch der Schnitt des Präparates ein günstiger sein. Trotz aller Bemübungen gelang es Brunn ebensowenig wie Kolossow, die physiologische Bedeutung dieser Härchen zu ergründen.

Die Untersuchungen Mönckebergs ${ }^{38}$ über endotheliale Zellen der serösen Höhlen erwiesen gleichfalls die charakteristischen Härchen, wie sie vor ihm Kolossow und Brunn gesehen hatten, wodurch die Beobachtungen dieser beiden Autoren vollständig bestätigt wurden.

Man kann es also auf Grund derBeobachtungen Kolossows, Brunns und Mönckebergs als bewiesene Tatsache annehmen, daß den früher als Endothelien betrachteten serösen Deckzellen nicht nur mit Rücksicht auf ihre Lage, sondern auch auf ihren Bau der Name "Epithel" vollkommen zusteht. Die Tatsache, daB auch an ihnen Flimmern entdeckt sind, ist 
so eigenartig und charakteristisch, daB uns die Annahme einer nahen Verwandtsehaft der platten Flimmerzellen in den von uns beobachteten Zysten mit den serösen Deekzellen, namentlich denen des Peritonaeums, rollkommen berechtigt erscheint.

Man könnte zwar noch an ihre Verwandtschaft mit den Flimmerzellen der an dem kleinen Becken lokalisierten kleinen Zystchen denken, jedoch diese Fälle zeigen prinzipielle Unterschiede mit dem von uns beobachteten Falle. Die Zystchen sind in diesen Fällen in großer Anzahl verstreut und voneinander getrennt an den inneren weiblichen Genitalorganen und am Peritonaeum des kleinen Beckens lokalisiert und unterscheiden sich auch schließlich durch die Form der Flimmerzellen selbst, welche in den Fällen Picks hoch und zylinderisch waren.

Wenn man auch annehmen könnte, daß die primäre Zellauskleidung der Zysten unter Einwirkung eines mechanischen Agens plattgedriickt werden konnte, so wäre wohl die Annahme, daßs so zarte Gebilde wie diese Härchen bei solchem Plattdrücken sich erhalten hätten, kaum möglich. Es spricht auch eine andere Tatsache gegen dieselbe.

Wir bemerken nämlich in einer Reihe von platten Zellen, wie oben beschrieben, plötzlich größere in das Lumen der Zyste hineinragende, ein Beweis, daß vom Innern der Zyste keinerlei mechanische Faktoren auf die Zellauskleidung einwirkten, da sie dieselbe vollkommen gleichmäßig plattgedrückt haben müßten.

Dasselbe kann aber anch als weiterer Beweis dafür gelten, daß die platten Zellen der Zellauskleidung unserer Zyste nicht der zylindrischen, sondern der halbrunden Zellform genetisch näherstehen.

Aus dem Gesagten geht hervor, daß in unserem Falle das Peritonaeum als Ausgangspunkt der Zyste angesehen werden muß und daß dieselbe in keiner Weise als eine Art Iymphatischer Zysten aufzufassen wäre.

Wollten wir unsere Zyste als eine Geschwulst von den Endothelien der Lymphgefäße ausgehend betrachten, so müßten wir auch annehmen, daß das Endothel der Lymphgefäße unter gewissen Bedingungen Flimmern trage, was jedoch bis jetzt von niemand beobachtet wurde. 
Nachdem wir in unserem Falle gar keine Veränderungen finden, welche auf die Entwicklung der Zysten im postembryonalen Leben hinweisen würden, keine deutlichen Zeichen eines entzündlichen Prozesses, keine Verwachsungen $u$. s. f., nachdem wir schließlich die Geschwulst so im Netzgewebe gelagert finden, daß uns die Annahme eines Entzündungsprozesses im extrauterinen Leben das Verständnis der Genese der multilokulären Zyste gar nicht erleichtern würde, scheint uns die Annahme am wahrscheinlichsten, daß der Ursprung derselben in a.bnormer embryonaler Entwicklung des Netzes zu suchen ist. Mit dieser Annahme stimmt auch die Tatsache überein, nach welcher auch in anderen Organen beobachtete multilokuläre Zysten ihren Ursprung vor allem in Entwicklungsabnormitäten haben würden (Zystenniere, Zystenleber, Enterokystom, Ovarialkystom).

Zum Schluß sei mir gestattet, Herrn Prof. Dr. Browicz und seinem Assistenten Herrn Prof. Dr. Ciechanowski in Krakau für mannigfache Unterstützung bei Abfassung dieser Arbeit meinen besten Dank aussprechen zu dürfen.

\section{Literatur.}

1. Ziegler, Allgemeine Pathologie, 1902.

2. Hedinger, Kasuistische Beiträge zur Kenntnis der Abdominalzysten. Dieses Arch., Bd. 16 .

3. Weichselbaum, Eine seltene Geschwulstform des Mesenteriums. Dieses Archiv, Bd. 64.

4. Werth, Arch. f. Gynäk., XIX.

5. Rokitansky, Lehrb. der pathol. Anat., 1855, Bd. I, S. 205.

6. Hahn, Berl. klin. Wochenschr., 1887, S. 408.

7. Tilger, Lymphzyste im Lig. hepatogastr. Dieses Archiv, Bd. 139, S. 288.

8. Lion, Ein Fall von Lymphzyste d. Lig. ut. lat. Dieses Archiv, Bd. 144, S. 239.

9. Heinrichs, Beiträge zur Geburtsh. u. Gyn. Festschr. f. Martin, 1895.

10. Ledderhose Über traumatische Lymphzysten. Dieses Archiv, 1894, Bd. 137, S. 197.

11. Wegner, Arch. f. klin. Chir, Bd. 20, S. 641. (Uber Lymphangiome. 
12. Bramann. Utber Chyluszysten d. Mesent. Arch. f. klin. Chir., 1887, Bd. 35, S. 201.

13. Winiwarter, Langenbecks Arch., Bd. 16, S. 6 อ5.

14. Boström, Killian, Berl. klin. Wochenschr., 1886, S. 407.

15. Virchow, Berl. klin. Wochenschr., 1887, S. 248.

16. Middeldorpf, Arch. f. klin. Chir., Bd. 31, S. 590.

17. Langhans, Kasuistische Beitr. zur Lehre v. d. Gefäßgeschw. Dieses Archiv, Bd. 75.

18. Schwarzenberger, Lymphkystom d. Oment. maj. Beitr. z. klin. Chir., Bd. t1.

19. Ris, Ein Fall v. Zyste d. großen Netzes. Brunns Beitr., 1893, Bd. X, S. 423.

20. Virchow, Dieses Archiv, Bd. 100.

21. Grawitz. (Nach Ris-Brunns Beitr., 1893, Bd. X, S. 423.)

22. Bergmann, Das multilokuläre Kyst. d. Netz. St. Petersbg. Med. Woch., 1897.

23. Henke, Multipl. zystisch. lymphangiomähnl. Tumor. der Bauchhöhle.

Verhandl. d. Deutsch. Path. Gesellsch., 1900, S. 251.

24. Renggli, Dissert. (Nach Henke, 23.)

25. Nager, Beitr. z. Kenntn. selt. Abdominaltum. Zieglers Beiträge, Bd. 36.

26. Merkel, Münch. med. Woch., 1904. 30. 1360.

27. Werth, Pseadomyxoma peritonaei. Arch. f. Gynäk., 1882, XXIV.

28. Fraenkel, E., Psendomyx. perit. Münch. med. Wochensch., 1901.

29. Rueder, Zentralbl. f. Gynäk., 1896, S. 173.

30. Kretschmer, Monatsschr. f. Geburtsh. Ergünzungsh. S. 32.

31. Olshausen, Veits Handb. d. Gynäk., III., S. 335.

32. Pfannenstiel (nach Werth, 27.)

33. Pick, Berl. klin. Woch. 1900, S. 219.

34. Kolossow, Über die Struktur des Pleuroperitonäal- u. Gefäßepithels

(Endothels). Arch. f. mikrosk. Anat., Bd. 42, 1893, S. 318.

35. Palladino, Extr. del Giorn. int. delle Science Mediche, Bd. 4, 1882 (nach Mönckeberg, 38.)

36. Büttner, Zieglers Beitr. Bd. 25, 1899, S. 453.

37. Brunn, Ziegl. Beitr., 1901, Bd. 30, S. 417.

38. Mönckeberg, Ziegl. Beitr., Bd. 34, 1903, S. 489.

39. Sick, Beitrag zur Lehre v. Bau u. Wachstum d. Lymphangiome. Dieses Archiv, Bd. 170. 